\title{
INTERACTIVITY WITHIN IMS LEARNING DESIGN AND QUESTION AND TEST INTEROPERABILITY
}

\author{
Onjira Sitthisak, Lester Gilbert, Mohd T Zalfan and Hugh C Davis \\ Learning Technologies Group, School of Electronics and Computing Science \\ University of Southampton, Highfield \\ Southampton, SO17 1BJ, United Kingdom \\ \{os05r,lg3, mtz04r, hcd\}@ecs.soton.ac.uk
}

\begin{abstract}
Keywords: Interactivity, Formative assessment, Learning design, IMS, QTI
Abstract: We examine the integration of IMS Question and Test Interoperability (QTI) and IMS Learning Design (LD) in implementations of E-learning from both pedagogical and technological points of view. We propose the use of interactivity as a parameter to evaluate the quality of assessment and E-learning, and assess various cases of individual and group study for their interactivity, ease of coding, flexibility, and reusability. We conclude that presenting assessments using IMS QTI provides flexibility and reusability within an IMS LD Unit Of Learning (UOL) for individual study. For group study, however, the use of QTI items may involve coding difficulties if group members need to wait for their feedback until all students have attempted a question, and QTI items may not be able to be used at all if the QTI services are implemented within a service-oriented architecture.
\end{abstract}

\section{INTRODUCTION}

E-learning can be viewed as the process of webbased or online learning within an open, flexible, and distributed learning environment (Westera et al., 2005). Although several web-based educational systems have been developed, these are ineffective for facilitating the reuse and sharing of either educational content or activities (Sampson et al., 2006).

The IMS Learning Design (LD) specification was introduced (IMS LD, 2003) to promote the exchange and interoperability of E-learning materials and to support pedagogical diversity. This specification offered a standardized way to associate educational content, activities and actors in the design of any teaching-learning process. Educational developers can use IMS LD to model who does what, when, and with which content and services in order to achieve the intended learning objectives.

The IMS QTI specification is used for exchanging assessment information such as questions, tests, and results. Similarly, it aims to promote the exchange and interoperability of assessment materials and services (IMS QTI, 2006).
We are looking into practices in the area of integration between IMS LD and IMS QTI. IMS QTI can be integrated with IMS LD in a number of ways, and questions arise about integrating IMS LD and IMS QTI from the point of view of pedagogical effectiveness. In particular, implementations may not sufficiently promote or control the desired interactivity experienced by learners, or may present an ineffective interactivity within the teachinglearning process.

In this paper, we consider the presentation of assessment and the resulting interactivity within an IMS LD Unit Of Learning (UOL) through the use of IMS QTI. First, the role of assessments and interactivity in the teaching-learning process is explored. Second, the basic ideas of IMS QTI and IMS LD are described. Third, various implementation cases of assessment in IMS LD are explained and their problems identified. Finally, the joint use of IMS QTI and IMS LD are evaluated in terms of improvement in flexibility, reusability, and other parameters in the provision of best-case interactivity expressible within a LD UOL. 


\section{INTERACTIVITY IN THE TEACHING AND LEARNING PROCESS}

The level of interactivity such as communication, participation, activity, and feedback has a major impact on the quality of technology enhanced learning. Consequently, "interactivity does not simply occur but must be intentionally designed" (Berge, 1999, p.5) into an E-learning system.

In an E-learning systems context, a cycle of interactivity occurs when the students are presented with a number of choices that requires them to actively process the course information and materials, and are then given prompt, contingent, and specific feedback about their particular choice. This view of interactivity is based upon principles from the psychology of learning. Figure 1 illustrates these key characteristics of the interactivity cycle (Gilbert and Gale, 2007).

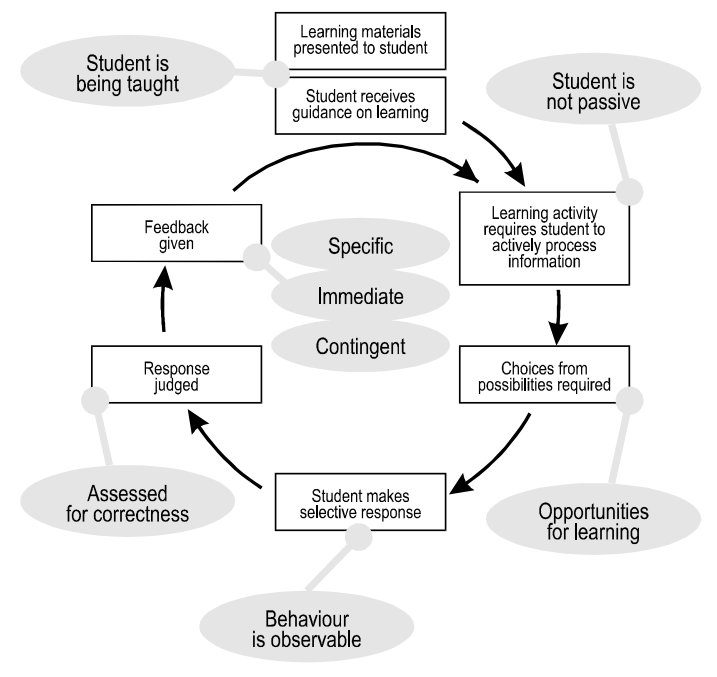

Figure 1: Characteristics of the interactivity cycle.

Interactivity begins when the student is required to process actively the materials and information. In order to ensure active processing of the materials, the student is posed a problem, question, or asked to undertake an activity that offers a number of options or choices. The student makes a choice, and receives feedback about that choice. The interactivity cycle completes, and the student continues with the next learning activity.

Rolfe and McPherson (1995, p. 837) note that "feedback or knowledge of results is the life-blood of learning". Appropriate feedback from assessment can motivate students and redirect their learning towards areas of deficiency, and can help teachers improve their coursework and instructional methods.

Assessments may be categorized as diagnostic, formative, or summative (McMillan, 2006). Formative assessment should be followed by feedback and remedial guidance so learners may know their deficiency in understanding, knowledge, or competence (Rolfe and McPherson, 1995).

Feedback is most effective and usable by the student when it is immediate, specific, and contingent (McKendree, 1990; King, 1999). Generally, feedback should be given immediately, or as soon as possible. Delayed feedback is usually less useful the more it is delayed, and is of course completely useless if it never arrives. The feedback must be specific if it is to be optimally effective. It is the specificity of the feedback that allows the students to focus on exactly those aspects of their learning that could do with improvement.

Most importantly, feedback must be contingent. This is a technical term that means the feedback must be functionally dependent upon, must follow and be linked to, the student's selective response. Effective feedback should incorporate these three factors in order to support a well-designed unit of learning.

In this paper we implement and evaluate interactivity using two specifications, IMS QTI and IMS LD, by expressing an UOL which involves the provision of feedback in formative assessment.

\section{THE IMS QTI SPECIFICATION}

The IMS QTI specification (IMS QTI, 2006) is a part of the same family of specifications as IMS LD. It describes an information model for representing questions, tests, and results. This specification enables the exchange of item; test, and results data between authoring tools, item banks, and test construction tools, as well as learning systems and assessment delivery systems. QTI version 2.0 processing is illustrated in Figure 2. 


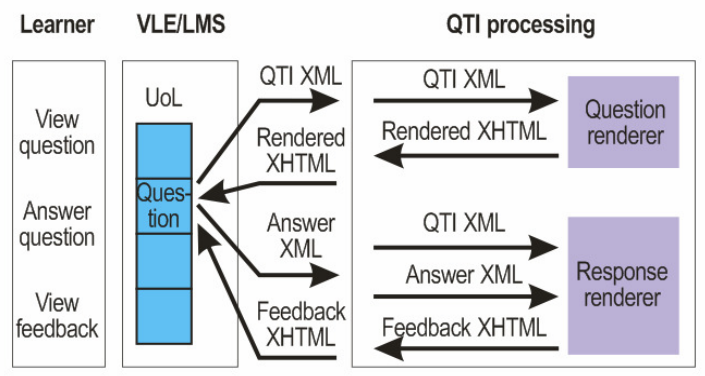

Figure 2: QTI version 2.0 processing.

When a learner accesses a Virtual Learning Environment or Learning Management System (VLE/LMS) to view and respond to a QTI question, the system initially sends a QTI XML file to a QTI processing service where a Question renderer renders the question, the rendered question is sent back to the VLR/LMS for display to the student. The learner's answer is sent to a QTI Response renderer which marks the answer and provides feedback. The rendered feedback is sent back to the VLE/LMS for display to the learner.

\section{THE IMS LD SPECIFICATION}

IMS LD (IMS LD, 2003) is based on the following principles: in a learning process each person has a role (learner or teacher) and achieves learning outcomes by carrying out learning activities within a supportive environment. The major concept of the IMS LD, the Method, is an element which allows the coordination of activities of each role in the designated environment to achieve learning objectives.

The learning process is modeled on a theatrical play from a structural point of view. A Method consists of one or more concurrent Play(s); a Play consists of one or more sequential Act(s); an Act consists of one or more concurrent Role-Part(s), and each Role-Part associates exactly one Role with one Activity or Activity-Structure.

In this study, we construct an IMS LD UOL to provide questions, check the correct answer and give feedback. We use Learning Design to orchestrate the above processes according to the interactivity cycle of Figure 1.

Activities in LD are associated with a Role in a Role-Part, and they contain the actual instruction for a person in that role. If the activity is directed at a learner and aims to achieve a specific learning outcome it is referred to as a learning activity.
A LD Method may contain conditions, i.e. If-ThenElse rules that further refine the assignment of activities and environment entities for persons and roles. The 'If' part of the condition uses Boolean expressions on the properties that are defined for persons and roles in the LD UOL. Properties are containers that can store information about persons' roles and about the UOL itself, e.g. user profiles, progression data (completion of activities), results of tests (e.g. prior knowledge, competencies, learning styles), or learning objects added during the teaching-learning process (e.g. reports, essays or new learning materials).

\section{ASSESSMENT CASES USING LEARNING DESIGN}

To explore assessments implemented using IMS LD, a small UOL was developed incorporating question and feedback activities. Students could see all question activities, and could access each question in turn. Interactivity was implemented as follows. First, a question with multiple answer choices was presented to each student. Next, the student responded to the question by selecting one of the choices. Then, the student's response was evaluated. Finally, the student received immediate, specific feedback relating to his or her particular answer. Then, the student moved forward to the second question where the pattern was repeated. This implementation may be considered 'individual' study. For a 'group' study implementation, a student was given the feedback of a question only after all students had finished answering it.

Using different mechanisms of Play, Act, condition elements, and activity conditions within IMS LD in order to control the interactivity, a number of different UOL cases were developed for the individual and group assessment scenarios. Because IMS QTI has the capability to encapsulate the question and feedback, each UOL case involving a question activity immediately followed by a feedback activity can be alternatively implemented as an IMS QTI item instead of being implemented within IMS LD.

Figure 3 shows an implementation structure of the assessment case for individual study using IMS LD alone. Figure 4 shows the implementation structure for individual study using assessment implemented as IMS QTI items. Figure 5 shows the implementation structure for group study using the assessment implemented as IMS LD items. 


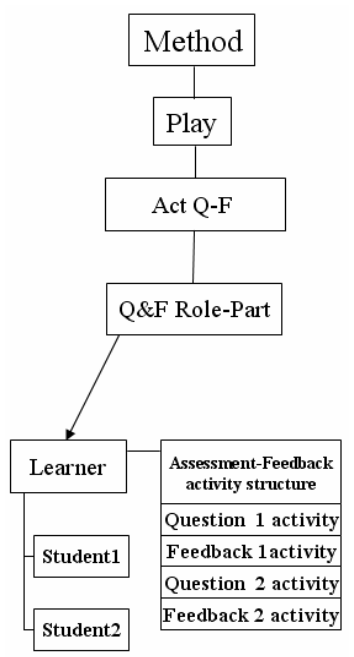

Figure 3: The structure of 'individual' study implementation IMS LD (illustrated with two students).

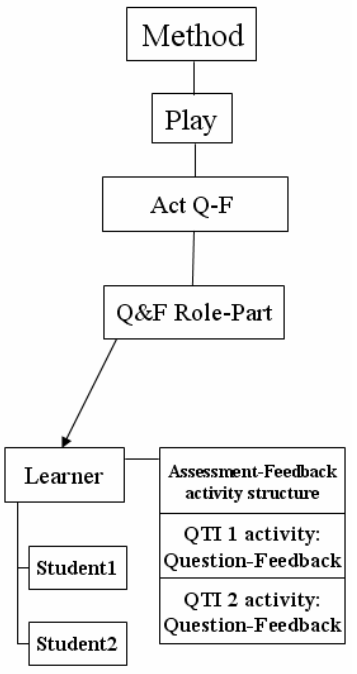

Figure 4: The structure of 'individual' study implementation IMS LD + QTI (illustrated with two students).

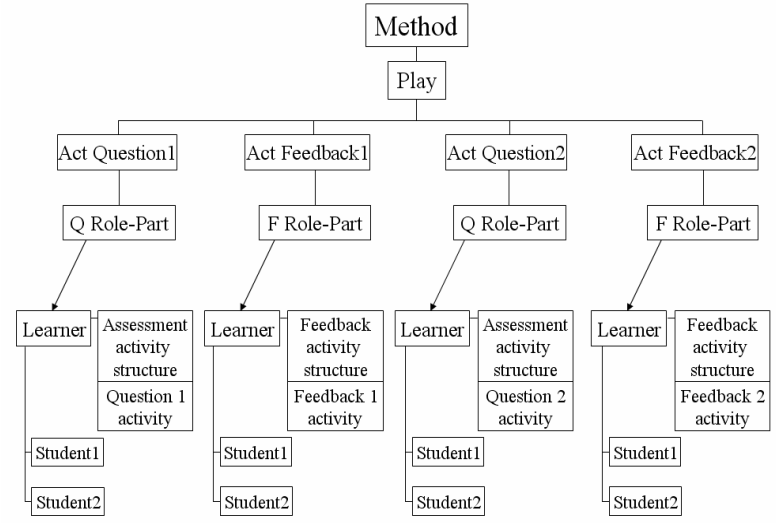

Figure 5: The structure of group study implementation using IMS LD (illustrated with two students).

\section{EVALUATION}

In this study, the criteria for evaluating the IMS LD UOL of 'individual' and 'group' implementations are as follows:

- Interactivity quality

The four criteria of interactivity quality are: the control of interactivity, and the specificity, immediacy, and contingency of feedback.

- Ease of coding

Ease of coding refers to the ease of providing the functionality needed in the implementation of each UOL.

- Flexibility and reusability

Flexibility and reusability refers to the ease with which the properties of the UOL can be changed and re-used in other contexts.

First, we consider the analysis of the simple UOL 'individual' implementation with one Play, one Act, and one Role-Part.

In Figure 3, when the question activity is completed, the feedback activity will be displayed immediately based on the result of answering the question. Hence, the IMS LD-only 'individual' implementation (Figure 3) provides full support for specificity, immediacy, and contingency of feedback.

Using the capability of IMS QTI to encapsulate the question activity and the feedback activity (Figure 4), the feedback message in the QTI activity will be displayed immediately when learners answer the question. As with the case of the LD-only structure, the LD + QTI UOL 'individual' implementation provides effective interactivity since feedback is immediate, specific, and contingent. 
Because IMS LD and IMS QTI provide mechanisms for controlling interactivity by using activity conditions, sequence/selection properties, and QTI mechanisms, the 'individual' implementations (Figure 3 and Figure 4) fully support ease of coding.

With regard to flexibility and reusability, the LDonly structure (Figure 3) provides partial support because changing, adding, or deleting the question and/or feedback requires re-coding the UOL. This is due to the dependency of the feedback activity on the result of answering in the question activity. However, this limitation may be addressed by implementing the assessments as IMS QTI items (Figure 4), increasing the flexibility and reusability of the UOL. The IMS QTI features provide for simpler coding within the UOL and enhance its reusability.

Second, we analyze the UOL 'group' implementations as follows. Due to the nature of the 'group' study, all group members need to complete the question activity before starting the feedback activity. Therefore, the learners may not get their feedback immediately after answering the question. However, they can still get specific and contingent feedback for their answers. As a result, a UOL 'group' implementation offers only partial support for immediate feedback, but with full support for specific and contingent feedback.

The LD-only UOL 'group' study implementation (Figure 5) provides for ease of coding through the use of the 'Act' LD structure to control interactivity. However, when implementing the assessment items as QTI items, there may be difficulties with coding within the UOL because IMS QTI may not provide sufficient support for controlling group interactivity.

As in the LD-only UOL 'individual' study implementation, the separation of question and feedback activities in the IMS LD-only UOL 'group' study implementation (Figure 5) the may cause difficulties with changing and re-using this UOL in other contexts. The 'group' study implementation of Figure 5 provides only partial support for flexibility and reusability. The LD + QTI 'group' implementation also provides only partial support for flexibility and reusability of implementation, but for a different reason. If group members need to wait for their feedback until all students have attempted a question, QTI items may not be appropriate. According to QTI processing (Figure 2), feedback is sent to the learner immediately after receiving the answer. Hence, it may not be possible to implement this version of 'group' study with QTI version 2.0 items by using rendering and response services within a service-oriented architecture.
Table 1 shows the analysis of the 'individual' study and table 2 shows the analysis of 'group' study assessment implementations using IMS LD alone and with IMS QTI.

Table 1: Analysis of 'individual' study assessment implementation.

\begin{tabular}{|c|c|c|}
\hline $\begin{array}{c}\text { Assessment } \\
\text { implementation }\end{array}$ & $\begin{array}{l}\text { LD-only } \\
\text { (individual) }\end{array}$ & $\begin{array}{c}\mathrm{LD}+ \\
\text { QTI(individual) }\end{array}$ \\
\hline Figure & Figure 3 & Figure 4 \\
\hline $\begin{array}{l}\text { Approach for } \\
\text { controlling } \\
\text { interactivity }\end{array}$ & $\begin{array}{l}\text { Activity condition, } \\
\text { sequence/selection } \\
\text { property }\end{array}$ & $\begin{array}{l}\text { QTI } \\
\text { mechanism }\end{array}$ \\
\hline $\begin{array}{l}\text { Immediate } \\
\text { feedback }\end{array}$ & Full support & Full support \\
\hline $\begin{array}{l}\text { Contingent } \\
\text { feedback }\end{array}$ & Full support & Full support \\
\hline Ease of coding & Full support & Full support \\
\hline $\begin{array}{l}\text { Flexibility and } \\
\text { Reusability }\end{array}$ & Partial support & Full support \\
\hline
\end{tabular}

Table 2: Analysis of 'group' study assessment implementation.

\begin{tabular}{|c|c|c|}
\hline $\begin{array}{c}\text { Assessment } \\
\text { implementation }\end{array}$ & $\begin{array}{l}\text { LD-only } \\
\text { (group) }\end{array}$ & LD + QTI (group) \\
\hline Figure & Figure 5 & Not illustrated \\
\hline $\begin{array}{l}\text { Approach for } \\
\text { controlling } \\
\text { interactivity }\end{array}$ & Act mechanism & $\begin{array}{l}\text { May not be } \\
\text { feasible depending } \\
\text { upon QTI service } \\
\text { implementation }\end{array}$ \\
\hline $\begin{array}{l}\text { Immediate } \\
\text { feedback }\end{array}$ & Partial support & Partial support \\
\hline $\begin{array}{l}\text { Contingent } \\
\text { feedback }\end{array}$ & Full support & Full support \\
\hline Ease of coding & Full support & Partial support \\
\hline $\begin{array}{l}\text { Flexibility and } \\
\text { Reusability }\end{array}$ & Partial support & Partial support \\
\hline
\end{tabular}

\section{DISCUSSION}

Table 1 and Table 2 illustrate two important issues.

First, in measuring the pedagogical effectiveness of any assessment, the model of interactivity shown in Figure 1 provides key indicators. These include the specificity, immediacy, and contingency of the feedback given to the student upon completion of the assessment. An instructional designer may evaluate an implementation of IMS LD and IMS QTI against these measures. 
Second, the IMS QTI specification can be considered as an integrative layer in implementing IMS LD UOLs. However, there are some shortcomings when integrating IMS QTI and IMS LD implementations, as discussed in the evaluation section. Instructional designers should consider this issue when integrating IMS QTI items within an IMS LD UOL.

\section{CONCLUSION}

The features of IMS QTI help the instructional designer to implement an assessment within an IMS LD UOL for individual study, solving the problems that we found: ineffective interactivity, difficulty of learning design coding, inflexibility, and poor reusability. Teachers are increasingly expected to create or adapt online activities without any technical support from specialists, and the use of IMS LD and QTI standards should help them meet these expectations. Future developments in IMS LD aim to improve the quality of e-learning, not only for educators, but also for learners, and aim to increase adaptation and reuse of UOLs (De Vries et al., 2006).

Our study suggests that interactivity may be used as a parameter for the pedagogical evaluation of assessment and E-learning. As a result, instructional designers are able to talk in terms of pedagogy rather than technology, making explicit pedagogical choices, subject to review, inspection, and critique.

Integration of IMS LD and IMS QTI would increase the value of UOLs, but attention needs to be paid to the usability of QTI items within 'group' study UOLs. The study and classification of group activities and typical interactivities will provide guidelines for developers to implement QTI and LD authoring and run-time tools which allow instructional designers to realize pedagogically informed UOLs.

\section{REFERENCES}

Berge, Z. L., 1999. Interaction in Post-Secondary Web-Based Learning. Educational Technology, Vol.39, No.1, pp 5-11.

De Vries, F., Tattersall, C. and Koper, R., 2006. Future developments of IMS Learning Design tooling. Educational Technology \& Society, Vol.9, No.1, pp 9-12.
Gilbert, L. and Gale, V., 2007. Principles of Elearning Systems Engineering, Chandos.

IMS LD, 2003. IMS Learning Design Best Practice and Implementation Guide. Available from http://www.imsglobal.org/learningdesign/ldv1p0/ imsld_bestv1p0.html

IMS QTI, 2006. IMS Question and Test Interoperability Overview. Available from http://www.imsproject.org/question/qti_v2p0/ims qti_oviewv2p0.html

King, J., 1999. Giving feedback. British Medical Journal, Vol.318, No.7200, pp 1-6.

McAndrew, P., Nadolski, R. and Little, A., 2005. Developing an approach for Learning Design Players. Journal of Interactive Media in Education 2005(14). Available from http://wwwjime.open.ac.uk/2005/14/

McKendree, J., 1990. Effective Feedback Content for Tutoring Complex Skills. Human-Computer Interaction, Vol.5, pp 381-413.

McMillan, J. H., 2006. Classroom Assessment: Principles and Practice for Effective Instruction, Pearson Technology Group.

Rolfe, I. and MaPherson, J., 1995. Formative assessment: how am I doing? The Lacent, Vol.345, No.8953, pp 837-839.

Sampson, D., Karampiperis, P. and Zervas, P., 2006. Authoring web-based learning scenarios based on the IMS Learning Design: Preliminary Evaluation of the ASK Learning Design Toolkit. IEEE, pp 1003-1010. Available from http://ieeexplore.ieee.org/iel5/10748/33913/0161 8475.pdf

Westera, W., Brouns, F., Pannekeet, K., Janssen, J. and Manderveld, J., 2005. Achieving E-learning with IMS Learning Design - Workflow Implications at the Open University of the Netherlands. Educational Technology \& Society, Vol.8, No.3, pp 216-225. Available from http://dspace.ou.nl/bitstream/1820/443/1/eLearni ng+withIMSLD.pdf 